EUROPEAN CENTRAL BANK

WORKING PAPER SERIES

NO. 324 / MARCH 2004

\title{
FUNDAMENTALS AND JOINT CURRENCY CRISES
}

by P. Hartmann, S. Straetmans and C. G. de Vries

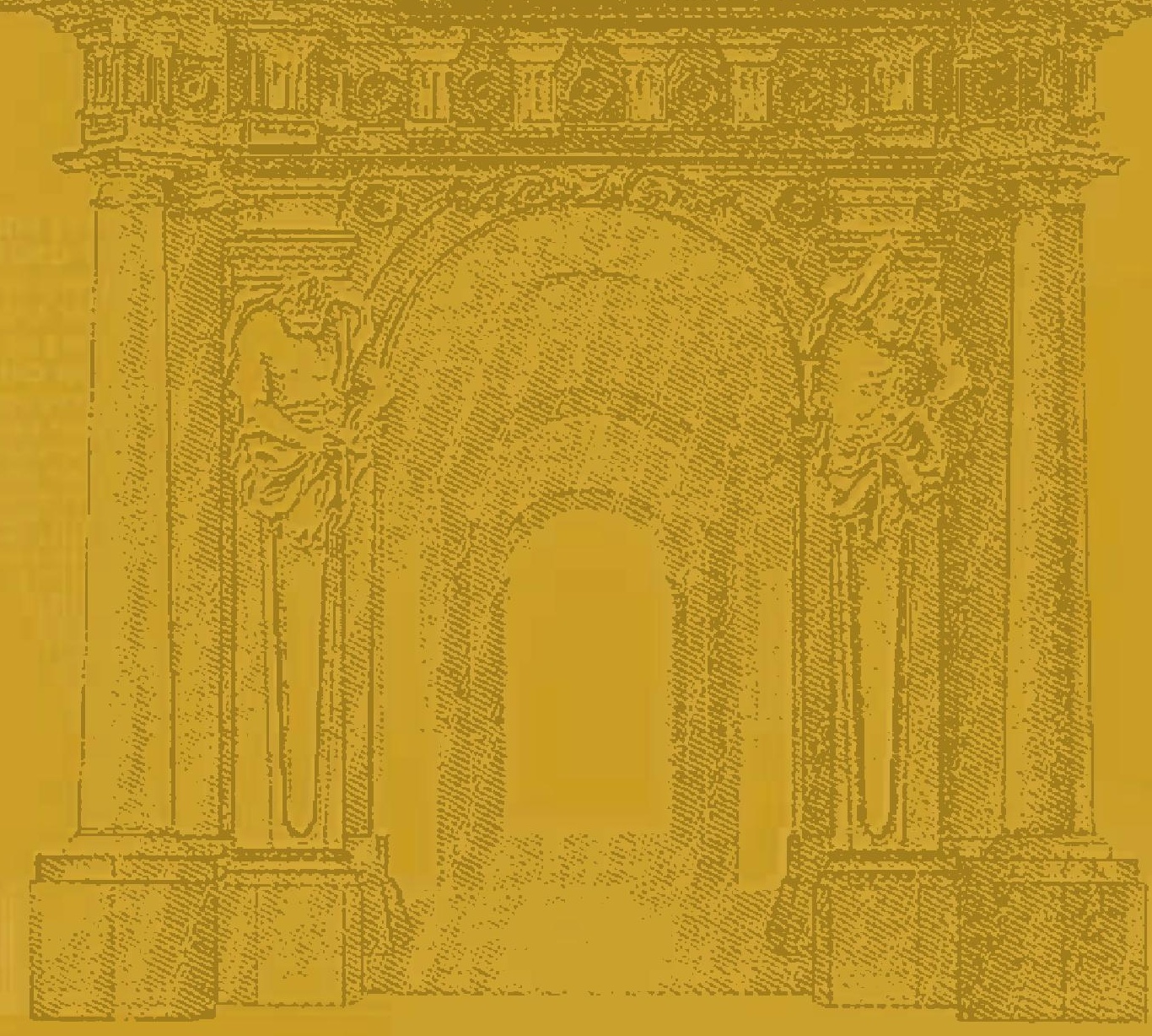




\title{
WORKING PAPER SERIES
}

N0. 324 / MARCH 2004

\author{
FUNDAMENTALS \\ AND JOINT \\ CURRENCY CRISES '
}

\author{
by P. Hartmann ${ }^{2}$, \\ S. Straetmans ${ }^{3}$ \\ and C. G. de Vries ${ }^{4}$
}

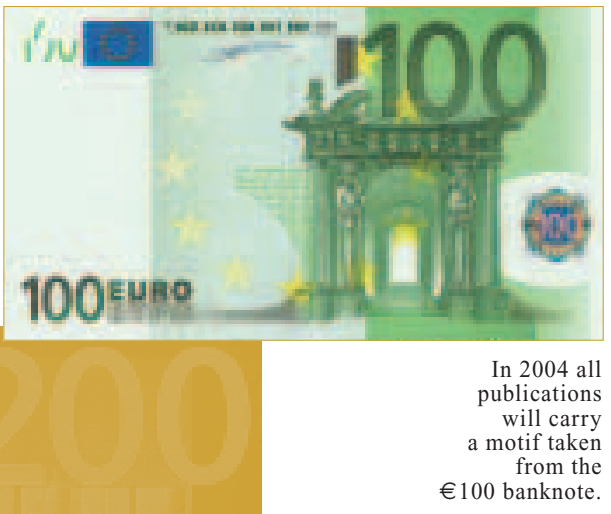

This paper can be downloaded without charge from http://www.ecb.int or from the Social Science Research Network electronic library at http://ssrn.com/abstract_id $=526987$.

\footnotetext{
I Any views expressed only reflect those of the authors and should not be interpreted as the ones of the ECB or the Eurosystem. 2 European Central Bank and CEPR, DG Research, Kaiserstraße 29, 603।I Frankfurt, Germany. E-mail address: philipp.hartmann@ecb.int.URL:http://papers.ssrn.com/sol3/cf_dev/AbsByAuth.cfm?per_id=2294/ 4 . 3 Limburg Institute of Financial Economics (LIFE), Economics Faculty, Maastricht University, P.O.Box 616, 6200 MD Maastricht, The Netherlands. E-mail address: s.straetmans@berfin.unimaas.nl. URL: $h$ ttp://www.fdewb.unimaas.nl/finance/faculty/straetmans/ 


\section{드 European Central Bank, 2004}

\section{Address}

Kaiserstrasse 29

60311 Frankfurt am Main, Germany

Postal address

Postfach 160319

60066 Frankfurt am Main, Germany

Telephone

+496913440

\section{Internet}

http://www.ecb.int

Fax

+496913446000

Telex

411144 ecb d

All rights reserved.

Reproduction for educational and noncommercial purposes is permitted provided that the source is acknowledged.

The views expressed in this paper do not necessarily reflect those of the European Central Bank.

The statement of purpose for the ECB Working Paper Series is available from the ECB website, http://www.ecb.int.

ISSN 1561-0810 (print)

ISSN 1725-2806 (online) 


\section{CONTENTS}

Abstract 4

Non-technical summary 5

1 Introduction 7

2. Affine exchange rate models $\quad 10$

3. Measures of dependence 10

3.1. The correlation measure $\quad 10$

3.2. Co-crash probabilities I|

4. Weak and strong currency crisis linkages $\quad$ |3

4.1. Fundamentals with light tails $\quad$ I4

4.2. Fundamentals with heavy tails $\quad 15$

5. Conclusion 18

References 2I

European Central Bank

working paper series

23 


\section{ABSTRACT}

In this note we demonstrate that in affine models for bilateral exchange rates, the nature of return interdependence during crises depends on the tail properties of the fundamentals' distributions. We denote crisis linkages as either strong or weak, in the sense that the dependence remains or vanishes asymptotically. We show that if one currency return reaches crisis levels, the probability that the other currency breaks down as well vanishes asymptotically if the fundamentals' distributions exhibit light tails (like e.g. the normal). However, if the marginal distributions exhibit heavy tails, the probability that the other currency breaks down as well remains strictly positive even in the limit. This result implies that linearity and heavy tails are sufficient conditions for joint or contagious currency crises to happen systematically through fundamentals.

Key words and phrases. Financial Crises, Currency Market Linkages, Fundamentals, Heavy Tails, Asymptotic Dependence JEL classification: G12, F31, G39, C49. 


\section{Non-technical summary}

Financial crises are usually described as failures of financial institutions or sharp falls in asset prices. Since long, there is an active debate about the origins and nature of such crises. For example, one view holds that they are the expression of an occasional inherent malfunctioning of financial institutions or markets, e.g. related to self-fulfilling events and sunspots. Another view rather sees crises as caused by bad outcomes in underlying economic variables (fundamentals). The primary concern with financial crises is that they can reach a large breadth, in the sense that banks fail or markets crash together. The reason for this concern is that these widespread (or systemic) crises have the strongest real effects, in that aggregate consumption, investment and growth are adversely affected. A recent literature on financial contagion and systemic risk has therefore started to pay attention to the breadth of crises. The present paper provides a new perspective on this issue. By combining exchange rate theory with multivariate extreme value analysis, we derive conditions under which widespread currency market crises occur systematically.

Within the context of a standard exchange rate model, we show that the magnitude of the crosscurrency interdependence during crisis periods hinges upon the statistical properties of extreme outcomes for the fundamental variables determining exchange rates. More specifically, if exchange rate returns are linearly related to domestic and foreign fundamentals, then different exchange rate returns against the same base currency are correlated. Nevertheless, we show that if one currency return reaches crisis levels, the probability that the other currency breaks down as well vanishes if the forex fundamentals have "thin tails" (i.e. extreme outcomes of fundamentals are very rare). In other words, joint currency crises are neither very frequent nor do they exhibit vehemence under this condition. Alternatively, if the fundamentals exhibit "heavy tails" (extreme fluctuations of fundamentals are less rare), the probability that the other currency breaks down as well remains strictly positive. In this case severe joint crises do happen relatively frequently. We develop our point in the context of exchange rates and currency crises, but the argument is more general, applying to crises in many financial markets.

Our main result is as simple as it may surprise. Two basic conditions are sufficient for systemic (widespread) currency market crises to occur frequently and with vehemence. First, the univariate distributions describing the behaviour of underlying economic variables are heavy tailed. Second, nominal bilateral exchange rates, expressed against the same currency, are linear expressions of 
the domestic and base currency fundamentals. The interesting and first novel element of this result is that the degree of cross-sectional dependence between exchange rate returns during crisis periods (so called asymptotic dependence), and thereby the breadth of currency crises, seems to be related to the univariate frequency of extreme realisations in macroeconomic fundamentals. The combination of asset pricing (here exchange rate) theory with extreme value analysis is the second, more methodological novel element of our paper. While fat tails and tail dependence of asset returns have by now been extensively documented in the empirical literature, how the marginal tail thickness relates theoretically to the bivariate tail dependence of returns in standard asset pricing models has - to the best of our knowledge - not been dealt with before.

Based on our analysis one may classify currency linkages during times of market stress into a weak and a strong type, depending on whether the conditional crash probability respectively vanishes or persists. Correspondingly, the international monetary and financial system may be characterised as being relatively stable in the former case, while it is more fragile in the latter case. Our two conditions, linearity and univariate heavy tails, are sufficient for having a more fragile system.

While the former condition is more intrinsic to the structure of the economy, the latter condition is related to economic policy, as public authorities can influence the distribution of underlying economic variables. If policy makers abstained from any action that may cause or accommodate extreme movements in economic fundamentals, then they would help avoiding widespread currency crises. In normal times this may mean e.g. to conduct monetary and fiscal policies with a steady hand, avoiding drastic changes in money supply or government expenditures. In very volatile times it may mean to counteract fluctuations in fundamentals through decisive action. In this fashion the frequency of extreme outcomes in underlying economic variables would be reduced. 


\section{INTRODUCTION}

Financial crises are usually described as failures of financial institutions or sharp falls in asset prices. Since long there is an active debate about the origins and nature of such crises. For example, one view holds that they are the expression of an occasional inherent malfunctioning of financial institutions or markets. Another view rather sees crises as caused by bad outcomes in underlying economic variables (fundamentals). Representative of the first view is the literature modelling univariate crises as self-fulfilling events in the presence of multiple equilibria (sunspots). For example, Diamond and Dybvig (1983) show that bank depositor runs can occur as a self-fulfilling prophecy, which would imply that they happen more or less randomly. Obstfeld (1986) argues that also currency crises can occur as a consequence of multiple equilibria. This is in contrast with the literature pointing to the fact that many such crises seem to have occurred in relation to unfavourable macroeconomic conditions, sometimes caused by bad policies. For example, Gorton (1988) makes forcefully the point that most episodes of banking instability in US history seem to have been related to business cycle downturns rather than occurring randomly. Krugman (1979) shows how unsustainably large budget deficits can lead to currency attacks.

The primary concern with financial crises is that they reach a large breadth, in the sense that banks fail or markets crash together. The reason for this concern is that these widespread (or systemic) crises have the strongest real effects, in that aggregate consumption, investment and growth are adversely affected. A more recent literature on financial contagion and systemic risk has therefore started to pay attention to the breadth of crises. For example, Allen and Gale (2000) model the spreading of bank failures through interbank exposures. Masson (1999) illustrates various forms of joint currency crises in a macroeconomic two-country model, covering both self-fulfilling and fundamentals-based crises. First empirical tests of joint currency crises have already been provided by Eichengreen, Rose and Wyplosz (1996) or Kaminsky and Reinhart (2000). ${ }^{1} \quad$ As understanding the spreading of financial crises is very important (for the reason given above), the present paper provides a new perspective on this issue. More specifically, by combining exchange rate theory with extreme value analysis, we derive conditions under which widespread crises occur systematically.

We develop our point in the context of exchange rates and currency crises, but - as we will explain below - the argument is more general, applying to crises in many financial markets. Within the context of a simple affine exchange rate model, we show that the magnitude of the cross-currency interdependence during crisis periods hinges upon the tail properties of the marginal distributions of the variables deter-

\footnotetext{
${ }^{1}$ For a broader survey of the contagion literature, see De Bandt and Hartmann (2000).
} 
minig exchange rates. More specifically, suppose that the logarithmic exchange rate returns are an affine function of the domestic and foreign fundamentals. This implies that different exchange rate returns against the same base currency are correlated. Nevertheless, we show that if one currency return reaches crisis levels, the probability that the other currency breaks down as well (increasing the threshold at which one speaks of a crisis without bound) vanishes asymptotically, if the forex fundamentals are thin tailed (e.g. normally distributed). In plain English, joint currency crises are neither very frequent nor do they exhibit vehemence under this condition. Alternatively, if the fundamentals exhibit heavy tails, the probability that the other currency breaks down as well remains stricly positive in the limit. In this case severe joint crises do happen relatively frequently.

Our main result is as simple as it may surprise. Two basic conditions are sufficient for systemic (widespread) currency market crises to occur frequently and with vehemence. First, the univariate distributions describing the behaviour of economic variables are heavy tailed. Loosely speaking, the heavy tail feature means that the probability of univariate currency collapses is much higher than what one would expect if the underlying fundamentals were normally distributed. Second, nominal bilateral exchange rates, expressed against the same currency, are linear expressions of the domestic and base currency fundamentals. The interesting and first novel element of this result is that the degree of cross-sectional dependence between exchange rate returns during crisis periods (so called asymptotic dependence), and thereby the breadth of currency crises, seems to be related to the univariate frequency of extreme realizations in macroeconomic fundamentals. We derive this result by combining standard exchange rate economics with multivariate statistical extreme value analysis. ${ }^{2}$ While fat tails and tail dependence of asset returns have by now been extensively documented in the empirical literature, ${ }^{3}$ how the marginal tail thickness relates theoretically to the bivariate tail dependence of returns in standard asset pricing models has - to the best of our knowledge - not been dealt

\footnotetext{
${ }^{2}$ Recently, a number of studies contributed to the financial contagion literature by employing multivariate extreme value analysis to estimate extreme asset return linkages (tail dependence). A first generation of papers provides bivariate analyses in the same asset class; see e.g. Straetmans (2000), Longin and Solnik (2001) and Poon et al. (2001) for stock markets and Starica (1999) and Hartmann et al. (2003) for foreign exchange markets. A second generation of papers either offers bivariate analyses across different asset classes, such as stock-bond linkages and the flight-toquality phenomenon in G-5 economies analyzed in Hartmann et al. (forthcoming), or higher order multivariate linkages.

${ }^{3}$ Since the seminal work by Mandelbrot (1963), numerous studies have estimated the tail thickness of univariate asset return distributions, generally finding more frequent crashes than would be predicted by the normal distribution. The relative occurrence of stock market extremes has by far received most of the attention; see e.g. Blattberg and Gonedes (1974), Jansen and de Vries (1991) or Jondeau and Rockinger (2003). Bond market extremes have been considered in Hartmann et al.
} 
with before. The combination of asset pricing (here exchange rate) theory with extreme value analysis is the second, more methodological novel element of our paper.

Based on this analysis one may classify currency linkages during times of market stress into a weak and a strong type, depending on whether the conditional crash probability respectively vanishes or persists asymptotically. Correspondingly, the international monetary and financial system may be characterized as being relatively stable in the former case, while it is more fragile in the latter case. Our two conditions, linearity and univariate heavy tails, are sufficient for having a more fragile system.

Our result has also some relevance for policy, as public authorities can influence the distribution of underlying economic variables. If policy makers abstained from any action that may cause or accommodate extreme movements in economic fundamentals, then they would help avoiding widespread currency crises. In normal times this may mean e.g. to conduct monetary and fiscal policies with a 'steady hand', avoiding drastic changes in money supply or government expenditures. In very volatile times it may mean to counteract fluctuations in fundamentals through decisive action. In this fashion the tails of the distributions of unerlying economic variables would be made thinner.

The remainder of this note proceeds as follows. In section 2 we introduce the canonical affine exchange rate model in which we study the relationship between marginal tail thickness and bivariate tail dependence. A discussion and comparison of different measures to characterize currency linkages during periods of market stress is provided in section 3. The central result of the note on the relationship between the univariate properties of economic fundamentals and the frequency and severity of exchange rate linkages during crises we derive in section 4. The two cases of thin tailed and fat tailed marginals are treated in two separate subsections. Finally, section 5 contains a summary and conclusions. 


\section{Affine Exchange Rate Models}

Consider the standard monetary model of the log price of currency $\mathrm{j}$ in terms of currency 0

$$
\begin{aligned}
s_{0 j} & =\left(m_{0}-\phi y_{0}+\lambda R_{0}\right)-\left(m_{j}-\phi y_{j}+\lambda R_{j}\right) \\
& =g_{0}-g_{j}, \quad j=1, \cdots, n .
\end{aligned}
$$

$g_{0}$ and $g_{j}$ are composite fundamentals consisting of the logarithmic money measure $m$, the negative of the income elasticity times log real income $-\phi y$ and the semi interest rate elasticity times the interest rate $\lambda R$ (see e.g. Frenkel, 1976, or Obstfeld and Rogoff, 1996, ch. 8). In first differences the monetary model can be concisely summarized as

$$
\Delta s_{0 j}=\Delta g_{0}-\Delta g_{j}
$$

The linear in first difference specification reveals two properties that will prove crucial in the following sections. First, the set of multiple exchange rates $\Delta s_{0 j}(j=1, \cdots, n)$ all have the fundamental $\Delta g_{0}$ in common. This exposure to shocks in the numéraire currency may be important, as illustrated e.g. in Aghion, Bachetta and Banerjee (2001). For a set of emerging market currencies, they plot the ratio of dollar denominated liabilities to claims with respect to foreign banks in 1997 right before the start of the Asian crisis. Given the high content of dollar denominated debt, most of the emerging market currencies were therefore highly exposed to the same US interest rate fluctuations. Second, (2.1) is linear in the first differences of the composite fundamental $g$ and hence the individual fundamentals as well. The linear specification conforms e.g. to the linear factor model used in Forbes and Chinn (2003), who show that trade linkages are important transmitters of shocks between countries. ${ }^{4}$

The use of linear models is by no means limited to the monetary model or the exchange rate literature, cf. the popular Arbitrage Pricing Theory for explaining equilibrium equity returns (Ross, 1976). Thus our results pertain to linkages between other classes of assets as well. Investment banks, for example, often hold sizable portfolios of commercial company equity. Sharpe fluctuations in the companies' equity portfolios in turn influence the banks' own shareholder value. As long as different investment banks hold stakes in the same companies with heavy tailed distributed returns, bank stocks are necessarily interdependent (see e.g. Acharya and Yorulmazer, 2003).

\section{Measures of DePendence}

3.1. The correlation measure. A standard measure of dependence is the coefficient of correlation $\rho$. As is well known the means, variances and the correlation coefficient of a pair of random variables completely characterize the bivariate normal distribution. One must ask, however, how well $\rho$ captures the dependence if it is unknown whether the data are normally distributed or not. Specifically, one wonders whether $\rho$ adequately captures the interdependence at crisis levels. Boyer, Gibson,

\footnotetext{
${ }^{4}$ Note that the monetary model captures the mirror image of the trade account through movements in the capital account.
} 
and Loretan (1997) have noticed that even if the normal model applies, verifying the market speak of increased correlation during times of crisis by calculating conditional correlation coefficients can be illusory. Forbes and Rigobon (2002) show that, indeed, if one corrects $\rho$ not much correlation change can be identified around crisis times.

One of the problems associated with the concept of correlation is that the data may be dependent, while the correlation coefficient is zero. Consider e.g. the discrete uniform distribution on the 8 points $(x, y) \in$ $\{(1,1),(1,-1),(-1,1),(-1,-1),(2,2),(2,-2),(-2,2),(-2,-2)\}$. Due to the symmetry of this distribution it is immediate that $\rho=0$, though the data are not independent. If $x=-1, y$ cannot be equal to 2 , and $P\{Y>1 \mid X>1\}=1 / 2$, while unconditionally $P\{Y>1\}=1 / 4$ only. Hence, $X$ and $Y$ are dependent and $\rho$ does not capture this dependence. $^{5}$

Lastly, economists evaluating investments within expected utility theory frameworks are not so much interested in the correlation measure itself; they rather have an interest in the trade-offs between risk measured as a probability and the gains or losses, which are the quantiles of the return distribution. As such the correlation is only an intermediate step in the calculation of this trade-off between quantile and probability. Therefore we like to turn to a measure which is not conditioned on a particular multivariate distribution and which directly reflects the probabilities and associated crash levels.

3.2. Co-crash probabilities. What is worrying for supervisors and industry representatives is that a heavy loss in one market goes hand in hand with a heavy loss in another market, destroying the real value of a diversified investment portfolio. More specifically, one asks given that $Y>s$, what is the probability that $X>s$, where $X$ and $Y$ stand for currency returns and $s$ is the common high loss level. ${ }^{6}$ Since we are interested in the extreme linkage probabilities, we will try to directly evaluate these probabilities, bypassing the correlation concept.

If two random variables $X$ and $Y$ are not independent, having some information about one variable, say $X$, implies that one has also information about the other variable, $Y$. This can be readily expressed as a conditional probability $P\{Y>s \mid X>s\}$. We will, however, adopt

\footnotetext{
${ }^{5}$ The bivariate Student-t distribution constitutes another popular example. Even if $\rho=0$, the model still exhibits dependence because the joint distribution cannot be factorized into the marginal dfs. In general, statistical or stochastic independence is sufficient for a zero correlation coeffiicent but not vice versa, see e.g. Feller (1971).

${ }^{6}$ Without loss of generality we can take the two quantiles on which we condition equal to $s$.
} 
the related probability measure that conditions on any market crash, without indicating the specific market. This is the linkage measure

$$
\frac{P\{X>s\}+P\{Y>s\}}{1-P\{X \leq s, Y \leq s\}}
$$

proposed in Hartmann et al. (forthcoming). The linkage measure, even though it is the sum of two conditional probabilities, reflects the expected number of currency crashes given that least one currency has collapsed. To see this, let $\kappa$ denote the number of simultaneously crashing currencies, i.e., returns exceeding $s$, and write the conditionally expected number of currency crashes given a collapse of at least one currency as $E\{\kappa \mid \kappa \geq 1\}$.

From probability theory we have that

$$
\begin{gathered}
E\{\kappa \mid \kappa \geq 1\}= \\
1 \frac{P\{X>s, Y \leq s\}+P\{X \leq s, Y>s\}}{1-P\{X \leq s, Y \leq s\}}+2 \frac{P\{X>s, Y>s\}}{1-P\{X \leq s, Y \leq s\}}= \\
\frac{P\{X>s\}+P\{Y>s\}}{1-P\{X \leq s, Y \leq s\}} .
\end{gathered}
$$

The conditional expectation measure $E\{\kappa \mid \kappa \geq 1\}$ has also the advantages that it can be easily extended beyond the bivariate setting and that one does not need to specify the crashing, conditioning asset whereby one would look only into one direction in the plane.

To develop some intuition for this measure as a device for measuring dependence during times of market stress, consider two polar cases.

Case 1. If $X$ and $Y$ are independent and identically distributed (i.i.d.) and writing $p=P\{X>s\}$, then

$$
E\{\kappa \mid \kappa \geq 1\}=\frac{2 p}{1-(1-p)^{2}}=\frac{2}{2-p} .
$$

In the limit $p \rightarrow 0$ as $s \rightarrow \infty$, and hence $E\{\kappa \mid \kappa \geq 1\} \rightarrow 1$.

Case 2. If $X=Y$ and writing $p=P\{X>s\}$, then

$$
E\{\kappa \mid \kappa \geq 1\}=\frac{2 p}{1-(1-p)}=2 .
$$

Clearly, even as $p \rightarrow 0$, still $E\{\kappa \mid \kappa \geq 1\}=2$.

These two cases show that $1 \leq E\{\kappa \mid \kappa \geq 1\} \leq 2$. In case the return pair is completely independent (Case 1), $E\{\kappa \mid \kappa \geq 1\}$ reaches its lower bound for very large quantiles $s$, which implies that the data are also asymptotically independent. On the other hand, if the data are completely dependent, then in the limit $(s \rightarrow \infty), E\{\kappa \mid \kappa \geq 1\}$ will 
still equal 2 (complete asymptotic dependence). Also notice that even though in the first case the data are independent, the dependence measure $E\{\kappa \mid \kappa \geq 1\}$ is higher than 1 at all finite levels of $p$ since even with independent returns, there is a nonzero probability that 'two markets will crash, given that at least one market crashes'.

As for the intermediate case of imperfectly correlated returns $(\rho \neq 0$, $|\rho|<1$ ), either $E\{\kappa \mid \kappa \geq 1\}=1$ (asymptotic independence) or $1<$ $E\{\kappa \mid \kappa \geq 1\} \leq 2$ (asymptotic dependence), if the quantile $s$ gets large. In particular, one cannot rule out that currency returns are asymptotically independent in the presence of a nonzero correlation.

\section{WEAK AND STRONG CURRENCY CRISIS LINKAGES}

Within the affine currency model framework from section 2, we are now ready to prove that the limiting value of (3.1) critically depends on the tail properties of the marginal distributions of the currency fundamentals. We dub the crisis linkage as weak (asymptotic independence) whenever $E\{\kappa \mid \kappa \geq 1\}=1$ in the limit, and strong (asymptotic dependence) otherwise. If the former case applies, the international monetary and financial system is more stable as severe crises in one currency are not associated with crises in other currencies, whereas in the latter case it is subject to systemic risk and therefore more fragile. For example, the existence of only weak crisis linkages implies the absence of the statistically significant occurrence of currency contagion.

Assume that each of the countries' composite fundamentals $\Delta g$ in (2.1) is independent from all the other countries' composite fundamentals. Regarding the distribution of $\Delta g$, we either assume normality or that the distribution exhibits heavy tails in the sense that tail probabilities are declining as a power function of the quantile (to be made precise below). Notice that tails of the normal distribution are governed by the exponential function whereas a heavy tailed model like the Student-t exhibits a Pareto distribution-type decline. It is more or less a stylized fact that many asset returns are heavy tailed. We show that this necessarily leads to asymptotic dependence. Conversely, we also show that if the fundamentals exhibit light tails, such as the normal distribution, then the forex returns are asymptotically independent

In order to derive our main result it is sufficient to consider a three currency system with composite fundamentals $\Delta g_{0}=X, \Delta g_{1}=-Y$, and $\Delta g_{2}=-Z$ such that $\Delta s_{01}=X+Y$ and $\Delta s_{02}=X+Z$. We may assume that $X, Y$, and $Z$ are i.i.d. ${ }^{7}$

\footnotetext{
${ }^{7}$ In practice, basic fundamentals like money supplies, national income levels and interest rates cannot be considered as being independent across countries. However,
} 
4.1. Fundamentals with light tails. In this subsection we assume that $X, Y$ and $Z$ are standard normally distributed random variables. As normality is preserved under summation the pair of random variables $\left(\Delta s_{01}, \Delta s_{02}\right)$ exhibits a bivariate normal distribution with correlation coefficient $\rho=1 / 2$.

Proposition 1. If $\Delta s_{01}$ and $\Delta s_{02}$ follow a bivariate normal distribution with $\rho=1 / 2$, then $\lim _{s \rightarrow \infty} E\{\kappa \mid \kappa \geq 1\}=1$, so that the crisis linkage is weak.

In order to prove this claim we use Sibuya's (1960) approach and the following asymptotic expansion for the tail probability of a normally distributed random variable:

$$
\operatorname{Pr}\{\theta X>s\} \sim \frac{1}{\sqrt{2 \pi}} \frac{\theta}{s} \exp \left(-\frac{1}{2}\left(\frac{s}{\theta}\right)^{2}\right), s \text { large }
$$

(see e.g. Abramowitz and Stegun, 1972, p. 932). To indicate equality in distribution we use the double arrow symbol " $\Rightarrow$ ".

Proof. We start by noticing that the expectational linkage measure (3.1) can be transformed as follows:

$$
\begin{aligned}
E\{\kappa \mid \kappa \geq 1\} & =\frac{\operatorname{Pr}\left\{\Delta s_{01}>s\right\}+P\left\{\Delta s_{02}>s\right\}}{1-\operatorname{Pr}\left\{\Delta s_{01} \leq s, \Delta s_{02} \leq s\right\}} \\
& =\frac{1}{1-\frac{\operatorname{Pr}\left\{\Delta s_{01}>s, \Delta s_{02}>s\right\}}{\operatorname{Pr}\left\{\Delta s_{01}>s\right\}+P\left\{\Delta s_{02}>s\right\}}} .
\end{aligned}
$$

Thus, we are left with proving that

$$
\lim _{s \rightarrow \infty} \frac{\operatorname{Pr}\left\{\Delta s_{01}>s, \Delta s_{02}>s\right\}}{\operatorname{Pr}\left\{\Delta s_{01}>s\right\}+P\left\{\Delta s_{02}>s\right\}}=0 .
$$

Evidently, the marginal tail probabilities in (4.2) are governed by the asymptotic expansion (4.1), e.g. for $\Delta s_{01}$ :

$$
\begin{aligned}
\operatorname{Pr}\left\{\Delta s_{01}>s\right\} & =\operatorname{Pr}\{X+Y>s\} \\
& \Rightarrow \operatorname{Pr}\{\sqrt{2} X>s\} \\
& \sim \frac{1}{\sqrt{\pi}} \frac{1}{s} e^{-s^{2} / 4}
\end{aligned}
$$

for large $s$. As for the joint exceedance probability in (4.2) an upward bound exists:

it can be easily shown that the relationship we derive between marginal tail heaviness and bivariate tail dependence still holds for pairwise dependent $X, Y$ and $Z$. The dependence - if present - actually even strengthens our results. By assuming independence we isolate the most difficult case to prove. 


$$
\begin{aligned}
\operatorname{Pr}\left\{\Delta s_{01}>s, \Delta s_{02}>s\right\} & \leq \operatorname{Pr}\left\{\Delta s_{01}+\Delta s_{02}>2 s\right\} \\
& =\operatorname{Pr}\{2 X+Y+Z>2 s\} \\
& \Rightarrow \operatorname{Pr}\left\{\frac{1}{2} \sqrt{6} X>s\right\} \\
& \sim \sqrt{\frac{3}{\pi}} \frac{1}{2 s} e^{-s^{2} / 3} .
\end{aligned}
$$

Thus, upon combining the last expressions and under the stated normality assumptions

$$
\begin{aligned}
\frac{\operatorname{Pr}\left\{\Delta s_{01}>s, \Delta s_{02}>s\right\}}{\operatorname{Pr}\left\{\Delta s_{01}>s\right\}+P\left\{\Delta s_{02}>s\right\}} & =\frac{\operatorname{Pr}\left\{\Delta s_{01}>s, \Delta s_{02}>s\right\}}{2 \operatorname{Pr}\left\{\Delta s_{01}>s\right\}} \\
& \leq \frac{\sqrt{3}}{4} \exp \left(-\frac{s^{2}}{3}+\frac{s^{2}}{4}\right) \rightarrow 0 \text { as } s \rightarrow \infty .
\end{aligned}
$$

Hence,

$$
\lim _{s \rightarrow \infty} E\{\kappa \mid \kappa \geq 1\}=1
$$

This asymptotic independence results is by no means limited to the class of normal distributions. A similar procedure can be used to verify the asymptotic independence for many other types of joint distributions. But the normal distribution appears most interesting, since it is so often assumed in theoretical and empirical work on exchange rate returns and in other asset pricing applications. Note that we have just shown that this assumption implies that currency (or other financial market) contagion cannot occur systematically.

4.2. Fundamentals with heavy tails. Prior to relating the tail fatness of exchange rate fundamentals to their degree of asymptotic dependence, we need a formal definition of what 'fat tails' exactly means. A random variable exhibits heavy tails if its distribution function $F(s)$ far into the tails has a first order term identical to the Pareto distribution, i.e.

$$
F(s)=1-s^{-\alpha} L(s) \quad \text { as } s \rightarrow \infty,
$$

where $L(s)$ is a slowly varying function such that

$$
\lim _{t \rightarrow \infty} \frac{L(t s)}{L(t)}=1, \quad s>0 .
$$


It can be easily shown that conditions (4.3)-(4.4) are equivalent to

$$
\lim _{t \rightarrow \infty} \frac{1-F(t s)}{1-F(t)}=s^{-\alpha}, \quad \alpha>0, s>0,
$$

i.e., the distribution varies regularly at infinity. The tail index $\alpha$ can be interpreted as the number of bounded distributional moments. And as not all moments are bounded, we speak of heavy tails. Distributions like the Student-t, F-distribution, Burr distribution, sum-stable distributions with unbounded variance all fall into this class. It can be shown that the unconditional distribution of the ARCH and GARCH processes belongs to this class as well. Note that Student-t distributions are often used in the empirical modelling of the unconditional return of exchange rates, see e.g. Boothe and Glassmann (1987), while GARCH process are extremely popular conditional models.

To derive our result, we need to use Feller's convolution theorem (Feller, 1971, VIII.8).

Theorem 1. Let $X_{i}$ be i.i.d. random variables with regularly varying symmetric tails, i.e. as $s \rightarrow \infty$

$$
\operatorname{Pr}\left\{X_{i} \leq-s\right\}=\operatorname{Pr}\left\{X_{i}>s\right\}=s^{-\alpha} L(s) .
$$

Then for the tail of the distribution of the sum of $X_{i}(i=1, \cdots, n)$ ( $n$-fold convolution) as $s \rightarrow \infty$

$$
\operatorname{Pr}\left\{\sum_{i=1}^{n} X_{i} \leq s\right\}=1-n s^{-\alpha} L(s) .
$$

In three dimensions this theorem implies by the independence of the $X_{i}$ that for large $s$

$$
\begin{aligned}
\operatorname{Pr}\left\{\sum_{i=1}^{3} X_{i} \leq s\right\} & \sim 1-\sum_{i=1}^{3} \operatorname{Pr}\left\{X_{i}>s\right\} \\
& \sim \operatorname{Pr}\left\{X_{1} \leq s\right\} \operatorname{Pr}\left\{X_{2} \leq s\right\} \operatorname{Pr}\left\{X_{3} \leq s\right\} \\
& =\operatorname{Pr}\left\{X_{1} \leq s, X_{2} \leq s, X_{3} \leq s\right\} .
\end{aligned}
$$

In other words, the probability on the area below the plane $\sum_{i=1}^{3} X_{i}=s$ equals the probability on the lower bar $\left\{X_{1} \leq s, X_{2} \leq s, X_{3} \leq s\right\}$. The first step is the Theorem 1. The second step is a consequence of the 
independence, which implies that the joint probability

$$
\begin{aligned}
\operatorname{Pr}\left\{X_{1} \leq s, X_{2} \leq s, X_{3} \leq s\right\} & =\operatorname{Pr}\left\{X_{1} \leq s\right\} \operatorname{Pr}\left\{X_{2} \leq s\right\} \operatorname{Pr}\left\{X_{3} \leq s\right\} \\
& =\left[1-s^{-\alpha} L(s)\right]^{3} \\
& =1-3 s^{-\alpha} L(s)+o\left(s^{-\alpha}\right) .
\end{aligned}
$$

Thus for large quantiles $s$ all mass concentrates along the axes, so that hyperplanes and bars that cut the three axes at the same points separate the same probability mass. This implies the following:

Proposition 2. Let $X, Y$ and $Z$ be i.i.d. random variables with regularly varying tails, i.e. as $s \rightarrow \infty$

$$
\begin{gathered}
\operatorname{Pr}\{X \leq-s\}=\operatorname{Pr}\{Y \leq-s\}=\operatorname{Pr}\{Z \leq-s\}=s^{-\alpha} L(s), \\
\operatorname{Pr}\{X>s\}=\operatorname{Pr}\{Y>s\}=\operatorname{Pr}\{Z>s\}=s^{-\alpha} L(s) .
\end{gathered}
$$

Then

$$
\lim _{s \rightarrow \infty} E\{\kappa \mid \kappa \geq 1\}=\frac{4}{3}
$$

Proof. By definition

$$
\begin{aligned}
\lim _{s \rightarrow \infty} E\{\kappa \mid \kappa \geq 1\} & =\lim _{s \rightarrow \infty} \frac{\operatorname{Pr}\left\{\Delta s_{01}>s\right\}+P\left\{\Delta s_{02}>s\right\}}{1-\operatorname{Pr}\left\{\Delta s_{01} \leq s, \Delta s_{02} \leq s\right\}} \\
& =\lim _{s \rightarrow \infty} \frac{\operatorname{Pr}\{X+Y>s\}+\operatorname{Pr}\{X+Z>s\}}{1-\operatorname{Pr}\{X+Y \leq s, X+S \leq s\}} .
\end{aligned}
$$

By Feller's convolution theorem 1 we directly have for the numerator in (4.6) that

$$
\operatorname{Pr}\{X+Y>s\}+\operatorname{Pr}\{X+Z>s\} \sim 2 s^{-\alpha} L(s)+2 s^{-\alpha} L(s) .
$$

For the denominator

$$
1-\operatorname{Pr}\{X+Y \leq s, X+Z \leq s\}
$$

note that the lines $X+Y=s$ and $X+Z=s$ are two of the three edges of the triangular plane $\sum_{i=1}^{3} X_{i}=s$ in the positive quadrant. We noted above that Feller's theorem implies that for large $s$ all mass is along the three axes. Hence, if we are interested in the joint probability of being below any two of the three edges of the triangular plane, this is necessarily equal to the probability of being below the triangular plane, since the set of two edges cuts the three axes at the same points (as the triangular plane). Hence,

$$
\begin{gathered}
1-\operatorname{Pr}\{X+Y \leq s, X+Z \leq s\} \sim 1-\operatorname{Pr}\{X+Y+Z \leq s\} \\
\sim 3 s^{-\alpha} L(s) .
\end{gathered}
$$


Thus

$$
\begin{aligned}
\lim _{s \rightarrow \infty} \frac{\operatorname{Pr}\{X+Y>s\}+\operatorname{Pr}\{X+Z>s\}}{1-\operatorname{Pr}\{X+Y \leq s, X+Z \leq s\}} & =\lim _{s \rightarrow \infty} \frac{2 s^{-\alpha} L(s)+2 s^{-\alpha} L(s)}{3 s^{-\alpha} L(s)} \\
& =\frac{4}{3} .
\end{aligned}
$$

The two exchange rates returns $\Delta s_{01}$ and $\Delta s_{02}$ are asymptotically dependent, since $\lim _{s \rightarrow \infty} E\{\kappa \mid \kappa \geq 1\}=4 / 3>1$. Thus the crisis linkage for this class of distributions is strong and the international monetary and financial system appears relatively fragile, exhibiting systemic risk.

Note, however, that proposition 2 does not imply that there are no joint distributions that have heavy tailed marginals, positive correlation and asymptotic independence. In fact one can easily verify that for e.g. the bivariate Gumbel-Pareto distribution

$$
F(x, y)=\left(1-x^{-\alpha}\right)\left(1-y^{-\alpha}\right)\left(1+\beta x^{-\alpha} y^{-\alpha}\right), \alpha>0,0<\beta<1,
$$

(constructed from the Farlie-Gumbel-Morgenstern copula) the marginals exhibit Pareto shapes, i.e., $F_{x}(s)=F_{y}(s)=1-s^{-\alpha}$ and that the two variates are not independent. Nevertheless, the distribution exhibits asymptotic independence. In this sense is the assumption about the linearity of asset returns in the fundamentals in proposition $2 \mathrm{cru}-$ cial. One can also construct joint distributions, where the marginals have exponential type thin tails, but which nevertheless exhibit asymptotic dependence. A systematic analysis of crisis linkages implied by non-linear exchange rate (or more general asset pricing) models is beyond the scope of this note and left to future research. The above result, however, implies that if the dependence arises from the linear properties of the problem, the marginals necessarily have to exhibit fat tails to obtain asymptotic dependence.

Finally, it has recently become popular to model dependence structures by chosing specific copulas. Proposition 2 shows that if economic theory implies that the dependence arises from a linear problem, then one should limit oneself to the subclass of copulas that are consistent with linearly induced asymptotic dependence.

\section{Conclusion}

It is by now well known that financial returns exhibit heavy tails and are thus nonnormally distributed. This implies that extreme market conditions tend to happen more frequently than expected on the basis of the normal distribution, which is used so often in standard asset 
pricing approaches. From the point of view of international financial stability and portfolio diversification, the strength of asset linkages during crisis periods matters even more, as the linkages determine the stability of the system as a whole. Several papers talk about increased correlation between financial assets or markets during crisis periods. As has been argued before, the use of correlation analysis is not without problems though. Since the correlation concept is just an intermediary step in calculating probabilities, we prefer to define market linkages in terms of conditional probabilities and the expected number of market crashes.

In the present paper we try to make two contributions. First, we make a first step to combine foreign exchange theory with extreme value analysis, so as to better understand the nature of market linkages in crisis periods. Second, we examine the role of the univariate properties of economic fundamentals for the strength and severity of extreme market spillovers. Choosing the case of currency markets we show that the fragility of the international monetary and financial system or its systemic stability hinges critically on the type of marginal distribution that applies to the country fundamentals. More precisely, we demonstrate that in linear exchange rate models the nature of interdependence between different currencies in times of crisis is fundamentally related to the univariate frequency with which large movements in underlying economic variables occur.

Suppose that logarithmic exchange rate returns are a linear function of the domestic and foreign fundamentals. This implies that different exchange rate returns against the same base currency are correlated, because they have partly common fundamentals. Nevertheless, if one currency crashes, the probability that the other currency breaks down as well vanishes asymptotically if the forex fundamentals exhibit thin tails, as the case for the normal distribution. Alternatively, if the marginal distributions exhibit heavier tails than the normal, e.g. are Student-t distributed, the probability that the other currency breaks down as well remains strictly positive even in the limit. We therefore speak of, respectively, weak and strong crisis linkages between different currencies. Correspondingly, the international monetary and financial system may be characterized as relatively robust in the former case, where destabilising phenomena like contagion do not occur systematically, while it is relatively fragile in the latter case.

Two simple conditions are sufficient for the spreading of financial instability to be directly related to the distribution of the economic fundamentals, fat tails and linearity. (We focus on exchange rates here, but the results apply to any other asset, as long as its pricing is 
linear and the marginals are heavy tailed.) While the latter condition is more intrinsic to the structure of the economy, the former condition is related to economic policy. In regular circumstances, by pursuing their policies with a 'steady hand' instead of orchestring drastic changes in variables like money supply, interest rates or public expenditure, public authorities can diminish the scope for fat tails in fundamentals. In specific circumstances of large market-driven fluctuations the same result can be attained through strong counteracting measures. In the light of our argument, policy institutions may in this way contribute to the stability of the international exchange rate system.

Two directions for future research emerge from the note. On the side of theory, it appears interesting to extend our analysis to nonlinear exchange rate (or asset pricing) models. Non-linear relationships between exchange rates and fundamentals could emerge from target zones (see Krugman, 1991) or from various forms of transaction costs (see e.g. Dumas, 1992). On the empirical side, the numerous studies of the tail behaviour of asset prices should be extended by systematic studies of the tail behaviour of the main macroeconomic fundamentals. This will indicate how frequent and severe spillovers of exchange market crises can be. Both directions are beyond the ambition of the present note. 


\section{REFERENCES}

[1] Abramowitz, M. and I.A. Stegun (1972), Handbook of Mathematical Functions, Dover, New York.

[2] Acharya, V.V. and T. Yorulmazer (2003), 'Information contagion and interbank correlation in a theory of systemic risk', CEPR Discussion Paper, no. 3743, February.

[3] Aghion, P., P. Bachetta, A. Banerjee (2001), 'Currency crises and monetary policy in an economy with credit constraints ', European Economic Review (Journal of the European Economic Association), 45, 1121-1150.

[4] Allen, F. and D. Gale (2000), 'Financial contagion', Journal of Political Economy, 108(1), 1-33.

[5] Blattberg, R.C. and N.J. Gonedes (1974), 'A comparison of the stable and student distributions as statistical models for stock prices', Journal of Business, 47, 244-280.

[6] Boothe and Glassmann (1987), 'The statistical distribution of exchange rates: empirical evidence and economic implications', Journal of International Economics, 22, 297-320.

[7] Boyer, B., M. Gibson, M. Loretan (1997), 'Pitfalls in tests for changes in correlation', International Finance Discussion Paper, no. 5-97, Board of Governors of the Federal Reserve System, December.

[8] De Bandt, O. and P. Hartmann (2000), 'Systemic risk: a survey', ECB Working Paper, no. 35, November.

[9] Diamond, D. and P. Dybvig (1983), 'Bank runs, deposit insurance, and liquidity', Journal of Political Economy, 91(3), 401-419.

[10] Dumas, B. (1992), 'Dynamic equilibrium and the real exchange rate in a spatially separated world', 5(2), Review of Financial Studies, 153-180.

[11] Eichengreen, B., A. Rose and C. Wyplosz (1996), 'Contagious currency crises: first tests', Scandinavian Journal of Economics, 98, 463-484.

[12] Feller, W. (1971), An Introduction to Probability Theory and its Applications, Vol. II, 2nd ed., Wiley, New York.

[13] Forbes, K.J. and R. Rigobon (2002), 'No contagion, only interdependence: measuring stock market comovements', Journal of Finance, 57, 2223-2262.

[14] Forbes, K.J., and M. D. Chinn (2003), 'A decomposition of global linkages in financial markets over time', NBER Working Paper, no. 9555.

[15] Frenkel, J.A. (1976), 'A monetary approach to the exchange rate: doctrinal aspects and empirical evidence', Scandinavian Journal of Economics, 78(2), 200-224.

[16] Gorton, G. (1988), 'Banking panics and business cycles', Oxford Economic Papers, 40, 751-781.

[17] Hartmann, P., S. Straetmans and C.G. de Vries (forthcoming), 'Asset market linkages in crisis periods', forthcoming Review of Economics and Statistics (ECB Working Paper, no. 71, Frankfurt, July 2000).

[18] Hartmann, P., S. Straetmans and C.G. de Vries (2003), 'A global perspective on extreme currency linkages', in W.C. Hunter, G.G. Kaufman and M. Pomerleano (eds.), Asset Price Bubbles: The Implications for Monetary, Regulatory and International Policies, MIT Press, Cambridge (MA), 361-382.

[19] Hols, M.C.A.B. and C.G. de Vries (1991), 'The limiting distribution of extremal exchange rate returns', Journal of Applied Econometrics, 6, 287-302.

[20] Jansen, D.W. and C.G. de Vries (1991), 'On the frequency of large stock returns: putting booms and busts into perspective', Review of Economics and Statistics, 73,19-24. 
[21] Jondeau, E. and M. Rockinger (2003), 'Testing for differences in the tails of stock-market returns', Journal of Empirical Finance, 10, 559-581.

[22] Kaminsky, G.I. and C.M. Reinhart (2000), 'On crises, contagion and confusion', Journal of International Economics, 51, 145-168.

[23] Koedijk, K.G., M.M.A. Schafgans and C.G. de Vries (1990), 'The tail index of exchange rate returns', Journal of International Economics, 29, 93-108.

[24] Krugman, P. (1979), 'A model of balance of payments crises', Journal of Money, Credit, and Banking, 11, 311-325.

[25] Krugman, P. (1991), 'Target zones and exchange rate dynamics', Quarterly Journal of Economics, 106(2), 651-667.

[26] Longin, F. and B. Solnik (2001), 'Extreme correlation of international equity markets', Journal of Finance, 56, 649-676.

[27] Mandelbrot, B. (1963), 'The variation of certain speculative prices', Journal of Business, 36, 394-419.

[28] Masson, P. (1999), 'Contagion: macroeconomic models with multiple equilibria', Journal of International Money and Finance, 18, 587-602.

[29] Mittnik, S., M.S. Paolella and S.T. Rachev (2000), 'Diagnosing and treating the fat tails in financial returns data', Journal of Empirical Finance, 7, 380416.

[30] Obstfeld, M. (1986), 'Rational and self-fulfilling balance of payments crises', American Economic Review, 76, 72-81.

[31] Obstfeld, M. and K. Rogoff (1996), Foundations of International Macroeconomics, MIT Press, Cambridge (MA).

[32] Poon, S.H., M. Rockinger and J. Tawn (2001), 'New extreme-value dependence measures and finance applications', CEPR Discussion Paper, no. 2762, London, April.

[33] Ross, S.A. (1976), 'The arbitrage theory of capital asset pricing', Journal of Economic Theory, 13, 341-360.

[34] Sibuya, M. (1960), 'Bivariate extreme statistics', Annals of the Institute of Statistical Mathematics, 11, 195-210.

[35] Starica, C. (1999), 'Multivariate extremes for models with constant conditional correlations', Journal of Empirical Finance, 6, 515-553.

[36] Straetmans, S. (2000), Extremal spill-overs in equity markets, in P. Embrechts (ed.), Extremes and Integrated Risk Management, Risk Books, London, 187204 . 


\section{European Central Bank working paper series}

For a complete list of Working Papers published by the ECB, please visit the ECB's website (http://www.ecb.int).

202 "Aggregate loans to the euro area private sector" by A. Calza, M. Manrique and J. Sousa, January 2003.

203 "Myopic loss aversion, disappointment aversion and the equity premium puzzle" by D. Fielding and L. Stracca, January 2003.

204 "Asymmetric dynamics in the correlations of global equity and bond returns" by L. Cappiello, R.F. Engle and K. Sheppard, January 2003.

205 "Real exchange rate in an inter-temporal n-country-model with incomplete markets" by B. Mercereau, January 2003.

206 "Empirical estimates of reaction functions for the euro area" by D. Gerdesmeier and B. Roffia, January 2003.

207 "A comprehensive model on the euro overnight rate” by F. R. Würtz, January 2003.

208 "Do demographic changes affect risk premiums? Evidence from international data" by A. Ang and A. Maddaloni, January 2003.

209 "A framework for collateral risk control determination" by D. Cossin, Z. Huang, D. Aunon-Nerin and F. González, January 2003.

210 "Anticipated Ramsey reforms and the uniform taxation principle: the role of international financial markets” by S. Schmitt-Grohé and M. Uribe, January 2003.

2II “Self-control and savings" by P. Michel and J.P. Vidal, January 2003.

212 "Modelling the implied probability of stock market movements" by E. Glatzer and M. Scheicher, January 2003.

213 “Aggregation and euro area Phillips curves” by S. Fabiani and J. Morgan, February 2003.

2I4 “On the selection of forecasting models" by A. Inoue and L. Kilian, February 2003.

215 "Budget institutions and fiscal performance in Central and Eastern European countries" by H. Gleich, February 2003.

216 "The admission of accession countries to an enlarged monetary union: a tentative assessment” by M. Ca'Zorzi and R. A. De Santis, February 2003.

217 "The role of product market regulations in the process of structural change" by J. Messina, March 2003. 
218 "The zero-interest-rate bound and the role of the exchange rate for monetary policy in Japan" by G. Coenen and V. Wieland, March 2003.

219 "Extra-euro area manufacturing import prices and exchange rate pass-through" by B. Anderton, March 2003.

220 "The allocation of competencies in an international union: a positive analysis" by M. Ruta, April 2003.

221 "Estimating risk premia in money market rates" by A. Durré, S. Evjen and R. Pilegaard, April 2003.

222 "Inflation dynamics and subjective expectations in the United States" by K. Adam and M. Padula, April 2003.

223 "Optimal monetary policy with imperfect common knowledge" by K. Adam, April 2003.

224 "The rise of the yen vis-à-vis the ("synthetic") euro: is it supported by economic fundamentals?" by C. Osbat, R. Rüffer and B. Schnatz, April 2003.

225 "Productivity and the ("synthetic") euro-dollar exchange rate" by C. Osbat, F. Vijselaar and B. Schnatz, April 2003.

226 "The central banker as a risk manager: quantifying and forecasting inflation risks" by L. Kilian and S. Manganelli, April 2003.

227 "Monetary policy in a low pass-through environment" by T. Monacelli, April 2003.

228 "Monetary policy shocks - a nonfundamental look at the data" by M. Klaeffing, May 2003.

229 “How does the ECB target inflation?" by P. Surico, May 2003.

230 "The euro area financial system: structure, integration and policy initiatives" by P. Hartmann, A. Maddaloni and S. Manganelli, May 2003.

231 "Price stability and monetary policy effectiveness when nominal interest rates are bounded at zero" by G. Coenen, A. Orphanides and V. Wieland, May 2003.

232 "Describing the Fed's conduct with Taylor rules: is interest rate smoothing important?" by E. Castelnuovo, May 2003.

233 "The natural real rate of interest in the euro area" by N. Giammarioli and N. Valla, May 2003.

234 "Unemployment, hysteresis and transition" by M. León-Ledesma and P. McAdam, May 2003.

235 "Volatility of interest rates in the euro area: evidence from high frequency data" by N. Cassola and C. Morana, June 2003. 
236 "Swiss monetary targeting 1974-1996: the role of internal policy analysis" by G. Rich, June 2003.

237 "Growth expectations, capital flows and international risk sharing” by O. Castrén, M. Miller and R. Stiegert, June 2003.

238 "The impact of monetary union on trade prices" by R. Anderton, R. E. Baldwin and D. Taglioni, June 2003.

239 "Temporary shocks and unavoidable transitions to a high-unemployment regime" by W. J. Denhaan, June 2003.

240 "Monetary policy transmission in the euro area: any changes after EMU?" by I. Angeloni and M. Ehrmann, July 2003.

24I Maintaining price stability under free-floating: a fearless way out of the corner?" by C. Detken and V. Gaspar, July 2003.

242 "Public sector efficiency: an international comparison" by A. Afonso, L. Schuknecht and V. Tanzi, July 2003.

243 “Pass-through of external shocks to euro area inflation” by E. Hahn, July 2003.

244 "How does the ECB allot liquidity in its weekly main refinancing operations? A look at the empirical evidence" by S. Ejerskov, C. Martin Moss and L. Stracca, July 2003.

245 "Money and payments: a modern perspective" by C. Holthausen and C. Monnet, July 2003.

246 "Public finances and long-term growth in Europe - evidence from a panel data analysis" by D. R. de Ávila Torrijos and R. Strauch, July 2003.

247 "Forecasting euro area inflation: does aggregating forecasts by HICP component improve forecast accuracy?" by K. Hubrich, August 2003.

248 "Exchange rates and fundamentals" by C. Engel and K. D. West, August 2003.

249 "Trade advantages and specialisation dynamics in acceding countries" by A. Zaghini, August 2003.

250 "Persistence, the transmission mechanism and robust monetary policy" by I. Angeloni, G. Coenen and F. Smets, August 2003.

25I "Consumption, habit persistence, imperfect information and the lifetime budget constraint" by A. Willman, August 2003.

252 "Interpolation and backdating with a large information set" by E. Angelini, J. Henry and M. Marcellino, August 2003.

253 "Bond market inflation expectations and longer-term trends in broad monetary growth and inflation in industrial countries, 1880-200I” by W. G. Dewald, September 2003. 
254 "Forecasting real GDP: what role for narrow money?" by C. Brand, H.-E. Reimers and F. Seitz, September 2003.

255 "Is the demand for euro area M3 stable?" by A. Bruggeman, P. Donati and A. Warne, September 2003.

256 "Information acquisition and decision making in committees: a survey" by K. Gerling, H. P. Grüner, A. Kiel and E. Schulte, September 2003.

257 “Macroeconomic modelling of monetary policy" by M. Klaeffling, September 2003.

258 "Interest rate reaction functions and the Taylor rule in the euro area" by P. GerlachKristen, September 2003.

259 "Implicit tax co-ordination under repeated policy interactions" by M. Catenaro and J.-P. Vidal, September 2003.

260 "Aggregation-theoretic monetary aggregation over the euro area, when countries are heterogeneous" by W. A. Barnett, September 2003.

261 "Why has broad money demand been more stable in the euro area than in other economies? A literature review" by A. Calza and J. Sousa, September 2003.

262 "Indeterminacy of rational expectations equilibria in sequential financial markets" by P. Donati, September 2003.

263 "Measuring contagion with a Bayesian, time-varying coefficient model" by M. Ciccarelli and A. Rebucci, September 2003.

264 "A monthly monetary model with banking intermediation for the euro area" by A. Bruggeman and M. Donnay, September 2003.

265 "New Keynesian Phillips Curves: a reassessment using euro area data" by P. McAdam and A. Willman, September 2003.

266 "Finance and growth in the EU: new evidence from the liberalisation and harmonisation of the banking industry" by D. Romero de Ávila, September 2003.

267 "Comparing economic dynamics in the EU and CEE accession countries" by R. Süppel, September 2003.

268 "The output composition puzzle: a difference in the monetary transmission mechanism in the euro area and the US" by I. Angeloni, A. K. Kashyap, B. Mojon and D. Terlizzese, September 2003.

269 "Zero lower bound: is it a problem with the euro area?" by G. Coenen, September 2003.

270 "Downward nominal wage rigidity and the long-run Phillips curve: simulation-based evidence for the euro area" by G. Coenen, September 2003.

27I "Indeterminacy and search theory" by N. Giammarioli, September 2003. 
272 "Inflation targets and the liquidity trap" by M. Klaeffling and V. López Pérez, September 2003.

273 "Definition of price stability, range and point inflation targets: the anchoring of long-term inflation expectations” by E. Castelnuovo, S. Nicoletti-Altimari and D. RodriguezPalenzuela, September 2003.

274 "Interpreting implied risk neutral densities: the role of risk premia" by P. Hördahl and D. Vestin, September 2003.

275 "Identifying the monetary transmission mechanism using structural breaks" by A. Beyer and R. Farmer, September 2003.

276 "Short-term estimates of euro area real GDP by means of monthly data" by G. Rünstler, September 2003.

277 "On the indeterminacy of determinacy and indeterminacy" by A. Beyer and R. Farmer, September 2003.

278 "Relevant economic issues concerning the optimal rate of inflation" by D. R. Palenzuela, G. Camba-Méndez and J. Á. García, September 2003.

279 "Designing targeting rules for international monetary policy cooperation" by G. Benigno and P. Benigno, October 2003.

280 “Inflation, factor substitution and growth" by R. Klump, October 2003.

28I "Identifying fiscal shocks and policy regimes in OECD countries" by G. de Arcangelis and S. Lamartina, October 2003.

282 "Optimal dynamic risk sharing when enforcement is a decision variable" by T. V. Koeppl, October 2003.

283 "US, Japan and the euro area: comparing business-cycle features” by P. McAdam, November 2003.

284 "The credibility of the monetary policy 'free lunch"' by J. Yetman, November 2003.

285 "Government deficits, wealth effects and the price level in an optimizing model" by B. Annicchiarico, November 2003.

286 "Country and sector-specific spillover effects in the euro area, the United States and Japan" by B. Kaltenhaeuser, November 2003.

287 “Consumer inflation expectations in Poland” by T. Łyziak, November 2003.

288 "Implementing optimal control cointegrated I(I) structural VAR models" by F. V. Monti, November 2003.

289 "Monetary and fiscal interactions in open economies" by G. Lombardo and A. Sutherland, November 2003. 
290 “Inflation persistence and robust monetary policy design” by G. Coenen, November 2003.

29I “Measuring the time-inconsitency of US monetary policy” by P. Surico, November 2003.

292 "Bank mergers, competition and liquidity" by E. Carletti, P. Hartmann and G. Spagnolo, November 2003.

293 “Committees and special interests” by M. Felgenhauer and H. P. Grüner, November 2003.

294 "Does the yield spread predict recessions in the euro area?" by F. Moneta, December 2003.

295 “Optimal allotment policy in the eurosystem's main refinancing operations?" by C. Ewerhart, N. Cassola, S. Ejerskov and N. Valla, December 2003.

296 "Monetary policy analysis in a small open economy using bayesian cointegrated structural VARs?" by M. Villani and A. Warne, December 2003.

297 “Measurement of contagion in banks' equity prices” by R. Gropp and G. Moerman, December 2003.

298 "The lender of last resort: a 2 I st century approach" by X. Freixas, B. M. Parigi and J.-C. Rochet, December 2003.

299 "Import prices and pricing-to-market effects in the euro area” by T. Warmedinger, January 2004.

300 "Developing statistical indicators of the integration of the euro area banking system" by M. Manna, January 2004.

301 “Inflation and relative price asymmetry” by A. Rátfai, January 2004.

302 “Deposit insurance, moral hazard and market monitoring” by R. Gropp and J. Vesala, February 2004.

303 "Fiscal policy events and interest rate swap spreads: evidence from the EU" by A. Afonso and R. Strauch, February 2004.

304 "Equilibrium unemployment, job flows and inflation dynamics" by A. Trigari, February 2004.

305 “A structural common factor approach to core inflation estimation and forecasting" by C. Morana, February 2004.

306 "A markup model of inflation for the euro area" by C. Bowdler and E. S. Jansen, February 2004.

307 "Budgetary forecasts in Europe - the track record of stability and convergence programmes" by R. Strauch, M. Hallerberg and J. von Hagen, February 2004.

308 "International risk-sharing and the transmission of productivity shocks" by G. Corsetti, L. Dedola and S. Leduc, February 2004.

309 "Monetary policy shocks in the euro area and global liquidity spillovers" by J. Sousa and A. Zaghini, February 2004.

310 "International equity flows and returns: A quantitative equilibrium approach" by R. Albuquerque, G. H. Bauer and M. Schneider, February 2004.

311 "Current account dynamics in OECD and EU acceding countries - an intertemporal approach" by M. Bussière, M. Fratzscher and G. Müller, February 2004. 
312 "Similarities and convergence in G-7 cycles" by F. Canova, M. Ciccarelli and E. Ortega, February 2004.

313 "The high-yield segment of the corporate bond market: a diffusion modelling approach for the United States, the United Kingdom and the euro area" by G. de Bondt and D. Marqués, February 2004.

314 "Exchange rate risks and asset prices in a small open economy" by A. Derviz, March 2004.

315 "Option-implied asymmetries in bond market expectations around monetary policy actions of the ECB" by S. Vähämaa, March 2004.

316 "Cooperation in international banking supervision" by C. Holthausen and T. Rønde, March 2004.

317 "Fiscal policy and inflation volatility" by P. C. Rother, March 2004.

318 "Gross job flows and institutions in Europe" by R. Gómez-Salvador, J. Messina and G. Vallanti, March 2004.

319 "Risk sharing through financial markets with endogenous enforcement of trades" by T. V. Köppl, March 2004.

320 "Institutions and service employment: a panel study for OECD countries" by J. Messina, March 2004.

321 "Frequency domain principal components estimation of fractionally cointegrated processes" by C. Morana, March 2004.

322 "Modelling inflation in the euro area" by E. S. Jansen, March 2004.

323 "On the indeterminacy of New-Keynesian economics" by A. Beyer and R. E. A. Farmer, March 2004.

324 "Fundamentals and joint currency crises" by P. Hartmann, S. Straetmans and C. G. de Vries, March 2004. 
